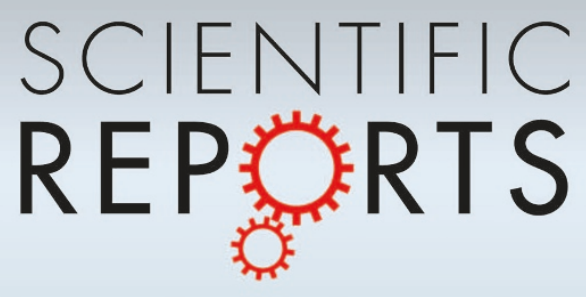

OPEN

SUBJECT AREAS:

CLIMATE SCIENCES

ATMOSPHERIC SCIENCE

ATMOSPHERIC DYNAMICS

Received

9 May 2014

Accepted

3 December 2014

Published

8 January 2015

Correspondence and requests for materials should be addressed to

M.N.K.

(mnkulk2005@gmail.

com)

\section{A new tool for predicting drought: An application over India}

\author{
M. N. Kulkarni
}

Indian Institute of Tropical Meteorology, Dr. Homi Bhabha Road, Pashan, Pune 411008 , State Maharashtra, India.

This is the first attempt of application of atmospheric electricity for rainfall prediction. The atmospheric electrical columnar resistance based on the model calculations involving satellite data has been proposed as a new predictor. It is physically sound, simple to calculate and not probabilistic like the standardized precipitation index. After applying this new predictor over India, it has been found that the data solely over the Bay of Bengal (BB) are sufficient to predict a drought over the country as a whole. Finally, two independent new methods to predict drought conditions and a preliminary forecast of the same for India for year 2014 have been given. Unlike the existing drought prediction techniques, the identification of drought conditions in a pre-drought year during 1981-1990 and 2001-2013 over India has been achieved $100 \%$ successfully using the suggested new methods. The association between rainfall and this new predictor has also been found on the sub-regional scale. So, the present predictor is expected to get global application and application in climate models. From the analysis, generally, a long period rising trend in aerosol concentration over the $\mathrm{BB}$ causes weak monsoon over India but that for a short time i.e. in pre-monsoon period strengthens it.

M oisture laden winds and the process of droplet formation are responsible for the rain formation. A monsoon in the Indian sub-continent is influenced by the geographical features such as mountains, plains etc. along with the oceanic, geophysical and atmospheric components. Several theories have been proposed to understand the origin and the process of monsoon but understanding of the phenomenon and its predictability are still not complete ${ }^{1}$.

The process of convection and aerosols in the atmosphere support the process of drop formation. So, a parameter which can serve as a partial measure of this complex non-linear phenomenon may be used for its predictability. Atmospheric electricity is one of the disciplines involving meteorological, geographical and environmental aspect, e.g., atmospheric ionization and aerosols. So, one can anticipate there could be a close association between the meteorological conditions and the parameters of global atmospheric electric circuit (GEC). A simple example is the reduction of atmospheric electrical conductivity in aerosol rich environment due to ionaerosol attachment which produces large ions of reduced mobility. Similarly, we find some more studies in literature supporting the above possibility, e.g., $60 \%$ increase in aerosol load increases the lightning flash frequency by $150 \%$ due to altered cloud microphysics ${ }^{2,3}$. This occurs because of reduced cloud ice particle size and delayed cloud ice glaciations to colder temperatures with increase in aerosol load ${ }^{3}$. The ionospheric potential $\left(V_{\mathrm{i}}\right)$ is the most fundamental characteristic of the GEC. Thunderstorms ${ }^{4-6}$, electrified shower clouds ${ }^{7,8}$, meso-scale convective systems ${ }^{9,10}$ are the meteorological generators which are believed to maintain the $V_{\mathrm{i}}$. Lightning may be playing primary ${ }^{11}$ or the secondary ${ }^{12}$ role. The long-term variation of the $V_{\mathrm{i}}$ corresponds to the atmospheric conductivity in-homogeneities determined by various natural and anthropogenic factors. So, the $V_{\mathrm{i}}$ can be used as an indicator of different physical processes in the atmosphere. The application of the $V_{i}^{13,14}$ as a global thermometer has been suggested. A comparison of $V_{i}$ variation with satellite images of high tropical cloud fields indicates that equatorial thunderstorms over the continents are dominant in maintaining the Earth's electric field. $V_{i}$ time series obtained at just one location may provide a high-resolution measure of intense tropical convection $^{15}$. The variations in the atmospheric electrical conductivity cause changes in the atmospheric electrical resistance which further cause resultant long term changes in the $V_{\mathrm{i}}$ i.e.in the GEC. These variations occur due to the variations in ionization processes such as cosmic ray ionization and surface radio activity, local change of aerosols caused due to man made activities and that in the source regions of the incoming air and convection. The global atmospheric electrical resistance is determined by all these factors as it is the resultant resistance when integrated over the globe. So, it is reasonable to have a atmospheric electrical predictor for predicting any meteorological event such as rain. 
Here, the atmospheric electrical columnar resistance $\left(R_{c}\right)$ has been suggested as a predictor for a drought occurrence. The technique has been applied over India.

$R_{\mathrm{c}}$ is a concept drawn from fair- weather atmospheric electricity $^{16,17}$. It is the resistance of a column of unit cross-section extending from the surface of the Earth to the ionosphere $(\sim 80 \mathrm{~km})$. Though the $R_{\mathrm{c}}$ is apparently a regional parameter, when integrated over the globe, constitutes the global resistance. In the aerosol rich environment and/or when the vertical convection is intense, one gets large values of the $R_{\mathrm{c}}{ }^{18}$. The expression to calculate $R_{\mathrm{c}}$ is based only on fair weather conditions and the vertical convection in boundary layer (BL) in the proposed model ${ }^{19}$. An atmospheric BL is that part of the atmosphere that directly feels the effect of the earth's surface. Its depth can range from just a few meters to few kilometers depending on the local meteorology. Atmospheric turbulence in BL tries to break the gradients of various atmospheric parameters. When steady state conditions prevail, the gradients of parameters (in this case the vertical gradients of atmospheric electrical conductivity) vanish and it is assumed that the conductivity remains almost unchanged in BL. This conductivity is the steady state conductivity $(\lambda(\infty))$ attained at the top of electrode layer (a layer of space charge near the electrode i.e. in the present case space charge layer near the earth's surface) ${ }^{20-23}$ which is in between the earth's surface and the top of BL. In highly turbulent conditions the top of electrode layer may reach the top of $\mathrm{BL}^{24} \cdot \lambda(\infty)$ continues in $\mathrm{BL}$ up to its top and may be considered as the average conductivity of BL. The expression of the columnar resistance $R_{\mathrm{c}}[=(H+S) / \lambda(\infty)]$, incorporates the intensity of convection through ' $H$ ' the planetary boundary layer height (PBLH), and the ion aerosol attachment process through the steady state conductivity $\lambda(\infty)$. ' $S$ ' is the scale height of conductivity ${ }^{19}$. The aerosol concentration is derived from the satellite measurements of aerosol optical $\mathrm{depth}^{25}$. The latitudinal cosmic ray ionization at the top of boundary layer is obtained using the cosmic ray ionization profiles ${ }^{26}$. The details of calculations have been given in the supplementary equations.

The $R_{c}$ is capable of showing signatures with the changing air mass as it depends upon the aerosol content in the vertical atmospheric column and the columnar aerosol distribution due to vertical convection. Changes in convection centers change the source regions of the air entering into the atmospheric column which in effect change the number concentration of aerosols and cloud condensation nuclei. Aerosol concentration in the atmosphere is related to lightning through cloud microphysics. Further, lightning creates major atmospheric effect by increasing atmospheric ozone levels and therefore may be considered as an active parameter. Such a major atmospheric effect has not been reported so far in case of $R_{\mathrm{c}}$ (seasonal $R_{\mathrm{c}}$ considered in the present analysis). This makes the use of $R_{\mathrm{c}}$ as a predictor easier.

Rainfall in tropical countries is a complex atmospheric process mainly dependent on a heating of a land and a degree of abundance of cloud condensation nuclei. Though, apparently there is no causeeffect relationship between the columnar resistance and rainfall, the main controlling factors for both the parameters are the aerosol content and convection. Since the circulations are driven by the differential solar heating causing vertical as well as horizontal convection, the columnar resistance and the rainfall are expected to vary with changes in circulations. So, it is expected that the $R_{\mathrm{c}}$ may serve as a predictor for monsoon.

\section{Results}

The area averaged data over the Bay of Bengal (BB) $\left(14.5^{\circ} \mathrm{N}-19.5^{\circ} \mathrm{N}\right.$, $85.5^{\circ} \mathrm{E}-90.5^{\circ} \mathrm{E}$ ) for total 120 months (January 1981-December 1990) and for total 156 months (January 2001- Dec2013) have been used separately for calculating the new predictor $R_{\mathrm{c}}$. The data in two different periods have been chosen because before year 2000, the ENSO (El Niño Southern Oscillations) were of canonical or of the eastern
Pacific type and after 2000, they are more of the Central Pacific type. Also, the required satellite data are not available during January 1993July 1996. The preliminary supporting figures to the results in Figures 1 and 2 are given in the supplementary online material.

Figure SM 1a shows the calculated steady state conductivities. Table SM 1 shows that the change in aerosol concentration is the basic requirement for the appreciable change in the $R_{\mathrm{c}}$ to occur. Figure SM $1 \mathrm{~b}$ and c show the variation of $R_{\mathrm{c}}$ versus the lag 3 and lag 1 all India rainfall (AIRF) for the period 1981-1990 and 20012012 respectively. Table SM 2 shows the derived air-earth current densities $\left(I_{\mathrm{t}}\right)$ from the previous measurements of the ionospheric potential $\left(V_{\mathrm{i}}\right)^{27}$ and the present calculated $R_{\mathrm{c}}$. Figure SM $1 \mathrm{~d}$ shows the scatter plots of the $I_{\mathrm{t}}$ and the lag $3 A I R F$ and the corresponding $R_{\mathrm{c}}$ and the lag $3 A I R F$. We can see that the $I_{\mathrm{t}}$ is in anti-correlation with the lag3 AIRF. Figures SM 1e and $\mathrm{f}$ show the variation of the filtered $R_{\mathrm{c}}$ (frequency range $0.0555-0.1$ cycles per month) and the lag 8 AIRF series for the period 1981-1990 and 2001-2012 respectively. The variation of the $R_{\mathrm{c}}$ series seems to be sufficiently organized with that of the AIRF series in the above figures to serve as a predictor.

The periodograms for the period 2001-2012 and 1981-1990 (Figures SM 2a,b,c \& d) show the dominant peak at the frequency 0.0833 cycles/month (annual periodicity) for the $R_{\mathrm{c}}$ and the AIRF series and two secondary peaks in the semi-annual frequency range.

When the monthly $R_{\mathrm{c}}$ series for both the periods is filtered using the FFT band pass filter or the recurrence filter (RF) based on the centered adjacent averaging method for the period 10 to 18 months (frequency range $0.0555-0.1$ cycles/month), it exhibits high anticorrelation (Spearman's rank correlation $\sim-0.85$ for the FFT filter and $\sim-0.79$ for the RF for the period 2001-2013, the correlation coefficient is $\sim-0.83$ for the period 1981-1990) with the AIRF series when the filtered $R_{\mathrm{c}}$ series leads by 8 months (Figure SM $3 \mathrm{a} \& \mathrm{~b}$ ). The correlations for both the periods are significant at more than $99.9 \%$ level of significance. The same exercise has been done for a small region (sub division in India) using a representative data over Pune $\left(18.5^{\circ} \mathrm{N}, 74^{\circ} \mathrm{E}\right)$ and found to be consistent with the result for all India (Figure SM 3c).

The standardized anomalies of the $R_{\mathrm{c}}$ and the AIRF are shown in Figures SM 4a \& c and SM 4b \& d respectively. These anomalies are calculated for the total period and then standardized for the individual years. The positive anomaly contours for the $R_{\mathrm{c}}$ and the AIRF are mostly concentrated during the pre-monsoon and monsoon period respectively. Figures SM 4e \& $\mathrm{f}$ show the time lag of 2 and 1 month respectively for the $A I R F$ percent maximum(based on total period) with respect to that for the $R_{\mathrm{c}}$.

Spearman's rank correlation coefficient $\sim-0.85$ between the $R_{\mathrm{c}}$ filtered series and the AIRF series of lag 8 is increased further to -0.93 when the $A I R F$ series is also filtered with the same band pass filter (Figure SM 5). This further confirms the use of $R_{\mathrm{c}}$ as a predictor for predicting rainfall conditions over India.

As any time series has three components: regular variation (cycles), irregular variation and trend, one can think that any special event like drought occurring intermittently may be considered as an outcome of the irregular variation and trend and may not be due to the regular cycles. So, it is required to separate out these components. Here, a method of de-seasonalizing of time series has been used for the $R_{\mathrm{c}}$ time series analysis. The anomalies $A_{1}$ of the resultant time series are standardized on the basis of respective total periods as there are two separate $R_{\mathrm{c}}$ series (1981-1990 and 2001-2013), and the anomalies $A_{2}$ are standardized on the basis of the individual year to incorporate the effect of trend as well as the inter-annual variability. We define $B(t)=A_{1}(t)+A_{2}(t)$ and $C(t)=A_{1}(t)-A_{2}(t)$ in each year for both the series, where ' $t$ ' is a time i.e. a month in the present monthly data. $B(t)$ and $C(t)$ have been normalized with the respective standard deviations for two separate total periods 1981-1990 and 2001-2013. Figure 1 indicates 10 panels, each for a single year from 1981 to 1990 .The monthly $B(t)$ and $C(t)$ are plotted on the $Y$-axis in 

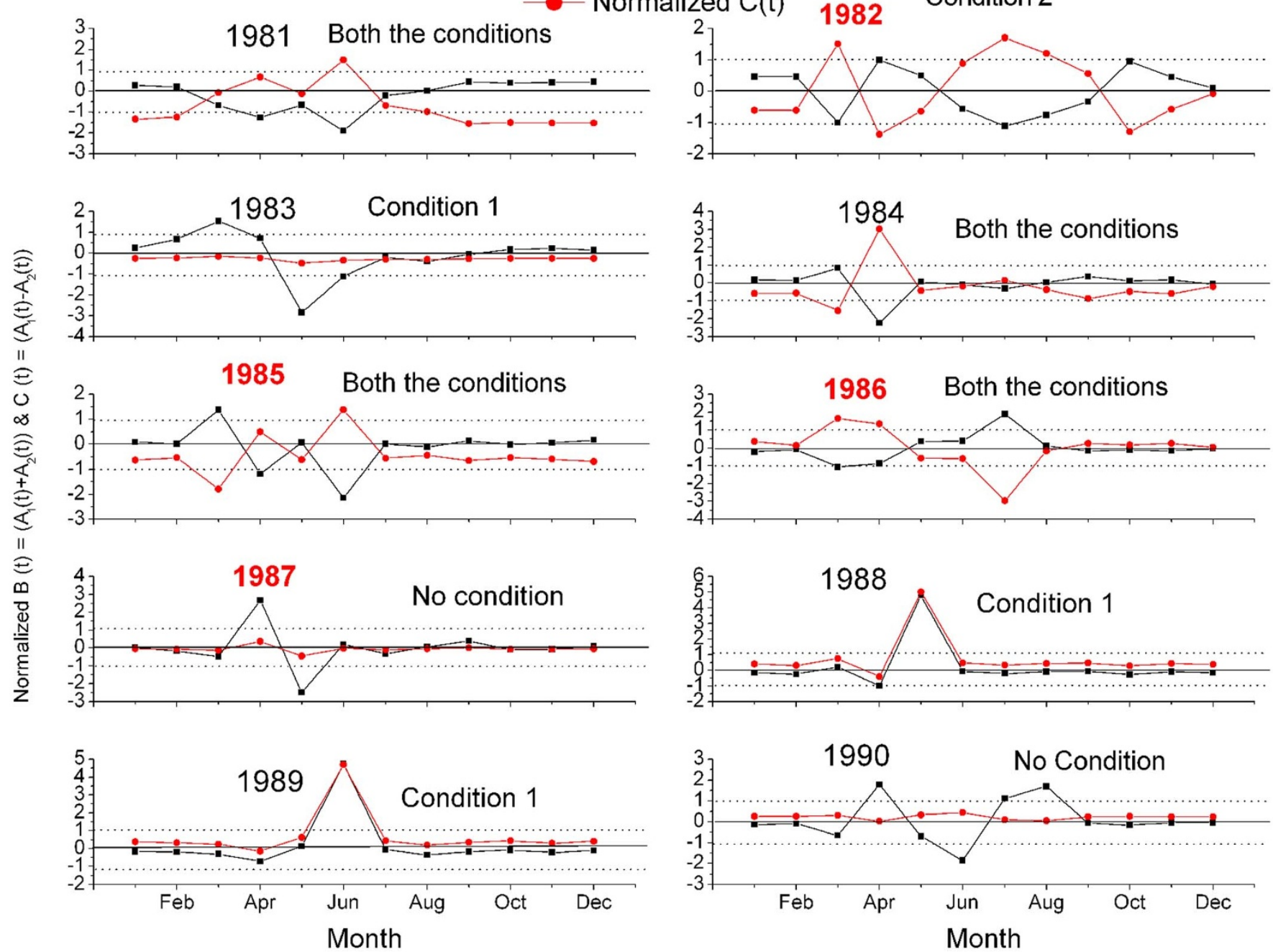

Figure $1 \mid$ Method 1: Plots of the normalized $B(t)$ and $C(t)$ for the period 1981-1990 to identify and predict drought years over India as a whole. $B(t)=$ $A_{1}(t)+A_{2}(t)$ and $C(t)=A_{1}(t)-A_{2}(t) . A_{1}(t)$ are the standardized $R_{\mathrm{c}}$ anomalies based on the total period and $A_{2}(t)$ are those based on the individual year. Drought years are indicated in red.

each panel with the corresponding months from January to December on the $X$-axis. Similarly, in Figure 2, $B(t)$ and $C(t)$ are plotted for the period 2001-2013. The dotted lines indicate $\pm \sigma$ (standard deviation). The major drought years given by the Indian Institute of Tropical Meteorology ${ }^{28}$ (supplementary methods) have been used initially for comparing our results. As the anti-correlation is very high $(>|0.8|)$ between the filtered $R_{c}$ and the AIRF series when the former series leads by 8 months, we look for the conditions in the previous year to predict conditions in the running year well in advance. We can see from Figure 1 and 2 that in the pre-drought year, (i) the absolute maximum amplitude of one polarity for $B(t)$ is $>1.5$ times of the maximum amplitude of the other polarity and (ii) The negative amplitude of $C(t)$ exceeds - $\sigma$ at least once in a pre-drought year when $C(t)$ in that year is of both the polarities and when $C(t)$ magnitudes are of single polarity (positive or negative), $C(t)$ exceeds $\pm \sigma$ at least once in a pre-drought year. In the years which are not followed by a drought year, these two conditions are not satisfied. In each panel of Figures 1 and 2 the fulfillment of these conditions is indicated. Also, Table 1 summarizes this method of drought prediction. We can see that from 1981-1990 and from 2001-2013, all droughts are identified using this technique without any exception. In year 2013, neither we see any prominent maximum of a single polarity of $B(t)$ nor the negative amplitude of $C(t)$ exceeding the $-\sigma$ line. So, it may be predicted that 2014 may not be a major drought year for India as a whole (i.e. the seasonal rainfall could be $\geq 90 \%$ of its long period average (LPA) from the criteria of the Indian Institute of Tropical Meteorology).

The another method of prediction is based on the number of positive columns of $A_{1}$ in a year $\left(N_{1}\right)$ and that of $A_{2}\left(N_{2}\right)$. Figures SM 6a $\&$ b show columns of $A_{1}$ and $A_{2}$ for the periods 1981-1990 and 2001-2013 respectively. The flow chart (Figure 3 ) is based on these number of columns and describes another independent scheme for predicting a drought over India. We can see from Figure 3 and Tables SM3a \& b that the drought can be predicted with the help of the number of anomalies of a single polarity and the ratio $(R)$ of the maximum and the minimum amplitude of $A_{1}$, the anomaly based on the long period statistics.

We can see from Figure SM $6 \mathrm{~b}$ and Table SM3b that $N_{1}=N_{2}=7$ $\geq 6$ for year 2013. So, from Figure 3, it is predicted that 2014 may not be a major drought year for India as a whole which is consistent with the forecast of the above first method.

To confirm the robustness of the technique, $R_{c}$ series has been calculated for Pune $\left(18.5^{\circ} \mathrm{N}, 74^{\circ} \mathrm{E}\right)$, a representative city in the Madhya Maharashtra sub-division (supplementary material) and checked with the corresponding sub-divisional rainfall. It also shows significant correlation of little less magnitude (Figure SM 4c). Thus, 

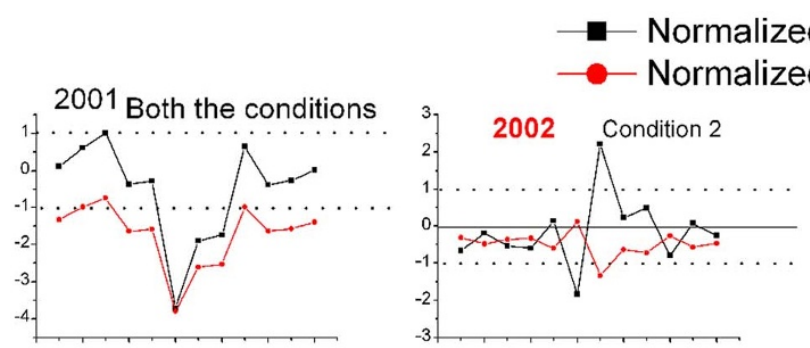

\section{$B(t)$}
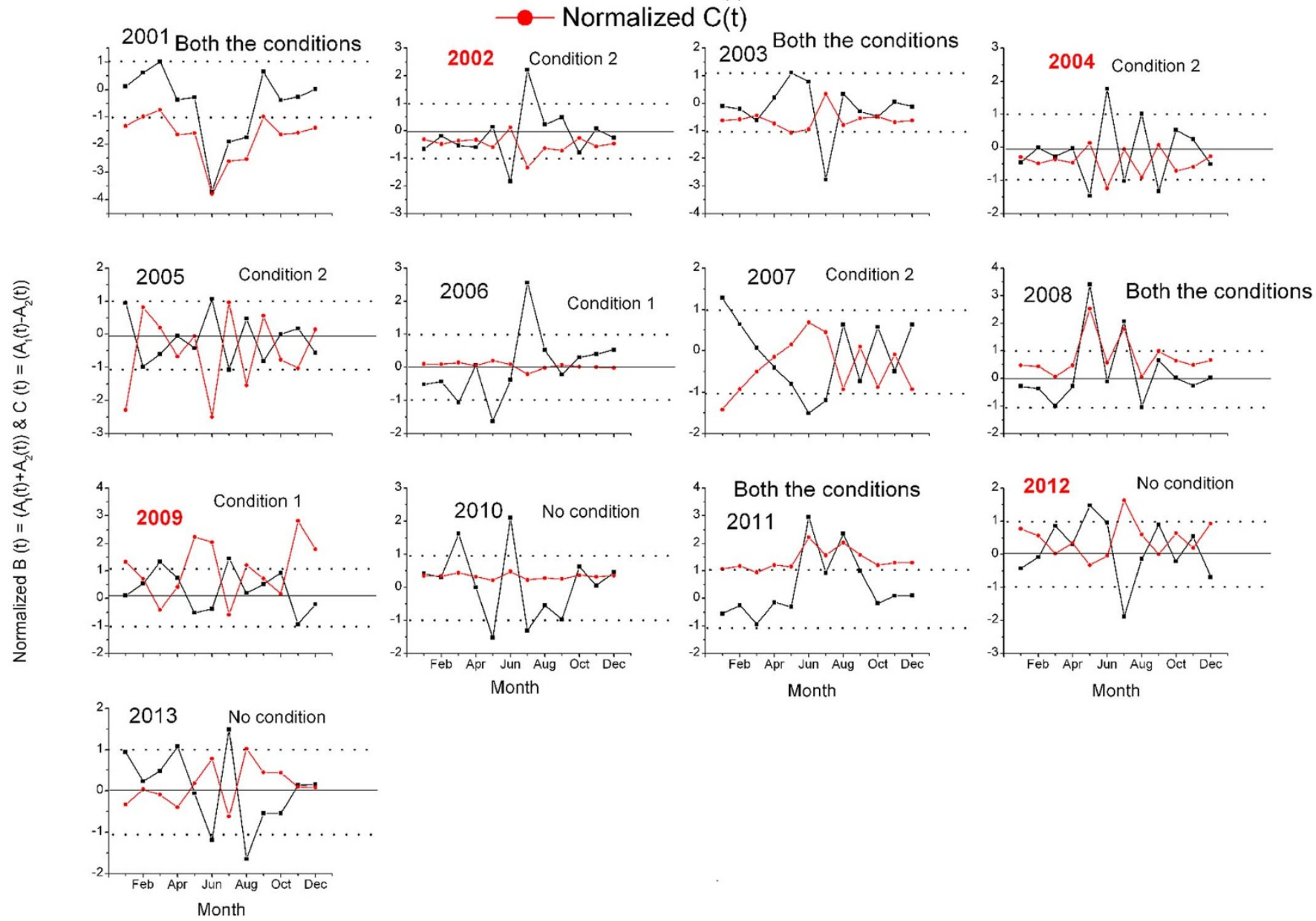

Figure $2 \mid$ Method 1: Plots of the normalized $B(t)$ and $C(t)$ for the period 2001-2013 to identify and predict drought years over India as a whole. $B(t)=$ $A_{1}(t)+A_{2}(t)$ and $C(t)=A_{1}(t)-A_{2}(t) . A_{1}(t)$ are the standardized $R_{\mathrm{c}}$ anomalies based on the total period and $A_{2}(t)$ are those based on the individual year. Drought years are indicated in red.

this technique may be useful for the Indian sub-regions too and may be applied for predicting a drought in future.

The above results may be summarized as follows: (i) A parameterization of $R_{\mathrm{c}}$ using the area averaged satellite data for the periods 19811990 and 2001-2013 over the BB serves as a potential predictor for predicting a drought over India during these periods. The lag anticorrelation between the AIRF series and the filtered $R_{\mathrm{c}}$ series over the $\mathrm{BB}$ is very high and highly significant. This is also examined on the sub-divisional scale over India. So. it is expected that in the future this may serve as a potential tool for prediction. (ii) The $R_{\mathrm{c}}$ and the AIRF series show dominant peak at annual frequency. (iii) The positive anomalies of $R_{\mathrm{c}}$ occur in the pre-monsoon period and those of AIRF in monsoon period showing the leading role of the $R_{\mathrm{c}}$ to the AIRF. (iv) The results show that the meteorological and environmental conditions over the $\mathrm{BB}$ alone are sufficient to predict a drought over India. The aerosol concentration and convection over the BB play major role in deciding rainfall over India. The high anti-correlation of the low frequencies of $R_{\mathrm{c}}$ (10-18 months) with the lag $8 A I R F$ and the positive correlation of $R_{\mathrm{c}}$ with the lag1/lag3 AIRF suggest that a long period increasing trend in aerosol concentration over the $\mathrm{BB}$ weakens the monsoon but strengthens it when it is for a short period of 1-3 months (pre-monsoon period). This is discussed further in more detail.

\section{Discussion}

The BB plays a major role in seasonal and intra-seasonal variability of monsoon due to its peculiar characteristics. The tropical cyclones originated in the $\mathrm{BB}$ play a major role in monsoon intra-seasonal variability and it is reported that intra-seasonal variability of the Indian monsoon could be resolved more by improving the prediction of tropical cyclones in the $\mathrm{BB}^{29}$. Also, the existence of the barrier layer, reversal of the upper ocean currents on seasonal and intraseasonal time scale with the corresponding Indian ocean dipole mode contribute for the intra-seasonal variability of monsoon ${ }^{30}$. The most important is it is an anomalous source of moisture. The CFSR (Climate Forecast System Reanalysis) model studies show that moisture supply from the $\mathrm{BB}$ and Arabian sea mainly determine the wet and dry years of India. On the other hand, model studies of National Centers for Environmental Prediction (NCEP)Department of Energy (DOE) Reanalysis report a major role of local evaporative sources from the continental regions. As moisture can advect from ocean surface to land over continents without precipitating immediately ${ }^{31-33}$, the role of the $\mathrm{BB}$ and Arabian sea cannot be considered secondary even accepting the results of the later model. The satellite estimates indicate that the northern $\mathrm{BB}$ is the site of the highest mean precipitation of the entire Asian monsoon region ${ }^{30}$ and perhaps of the global oceans ${ }^{34}$. A large amount of rainfall over the region may cause latent heating consequently driving the Asian monsoon circulation $^{34}$. The model simulations of the dynamics and convection of the region are not satisfactory ${ }^{34,35}$. Atmospheric General Circulation Model simulations of inter-annual variability of monsoon over Indian sub-continent are poor ${ }^{35}$. This is attributed to intra-seasonal variability. A more comprehensive analysis of 
Table $1 \mid$ Method 1: When $|\mathrm{K}|>1.5$ and $\mid-\sigma \max$ for $C(t) \mid>1$ (both the polarities of $C(t))$ or $| \pm \sigma \max |>1(C(t)$ is of single polarity) in a year then the forthcoming year could be a drought year. $|\mathrm{K}|=$ ratio of second and third column or third and second column whichever is maximum

\begin{tabular}{|c|c|c|c|c|c|c|c|}
\hline Year & $+\sigma \max$ for $B(t)$ & $-\sigma \max$ for $B(t)$ & K & Polarity of $C(t)$ & $+\sigma \max$ for $C(t)$ & $-\sigma \max$ for $C(t)$ & OUTCOME \\
\hline 1981 & 0.44 & -1.90 & -4.32 & Both + and - & Not required & -1.54 & START \\
\hline 1982 & 1.00 & -1.12 & -1.12 & Both + and - & Not required & -1.38 & Drought \\
\hline 1983 & 1.53 & -2.86 & -1.87 & Single - & NA & -0.49 & No Drought \\
\hline 1985 & 1.37 & -2.15 & -1.57 & Both + and - & Not required & -1.78 & Drought \\
\hline 1986 & 1.87 & -1.06 & -1.76 & Both + and - & Not required & -2.95 & Drought \\
\hline 1987 & 2.65 & -2.47 & -1.07 & Both + and - & Not required & -0.45 & Drought \\
\hline 1990 & 1.79 & -1.84 & -1.03 & Single + & 0.45 & NA & No Drought \\
\hline 2001 & 1.00 & -3.71 & -3.71 & Single - & NA & -3.80 & START \\
\hline 2002 & 2.21 & -1.86 & -1.19 & Both + and - & Not required & -1.34 & Drought \\
\hline 2003 & 1.11 & -2.78 & -2.50 & Both + and - & Not required & -1.07 & No Drought \\
\hline 2004 & 1.77 & -1.47 & -1.20 & Both + and - & Not required & -1.24 & Drought \\
\hline 2005 & 1.07 & -1.07 & -1.00 & Both + and - & Not required & -2.50 & No Drought \\
\hline 2011 & 2.95 & -0.94 & -3.14 & Single + & 2.22 & NA & No Drought \\
\hline 2012 & 1.47 & -1.88 & -1.28 & Both + and - & Not required & -0.33 & Drought \\
\hline 2013 & 1.48 & -1.65 & -1.11 & Both + and - & Not required & -0.62 & No Drought \\
\hline 2014 & & & & & & & No Drought \\
\hline
\end{tabular}

convective activity has been done for a large spatial domain ${ }^{36}$ but ignoring the unique conditions in the $\mathrm{BB}^{34}$. Thus, though it is a significant region to have enhanced observations over there for resolving monsoon variability ${ }^{29}$, we find quite a few studies on the $\mathrm{BB}^{30}$. Also, there are very few studies in atmospheric electricity conducted over the $\mathrm{BB}$.

The above discussion highlights the requirement of studies on the $\mathrm{BB}$ for the better understanding of monsoon and its association with the atmospheric electrical parameters. The selected region for the present analysis of $R_{c}$ series is $14.5^{\circ} \mathrm{N}-19.5^{\circ} \mathrm{N}$ and $85.5^{\circ} \mathrm{E}-90.5^{\circ}$ E. The results of the analysis are discussed below:

The $R_{\mathrm{c}}$ calculations involve the calculated steady state conductivities shown in Figure SM 1a.The present results of the steady state conductivity are found to be consistent with the previous few con- ductivity measurements over the BB. The measured average conductivity near the surface for total 9 fair weather days during August 1990 to September 1990 for the region $5^{\circ} \mathrm{N}-20^{\circ} \mathrm{N}$ and $74^{\circ} \mathrm{E}-89^{\circ} \mathrm{E}$ has been reported $\mathrm{d}^{37,38}$ as $0.86 \times 10^{-14} \mathrm{mho} \mathrm{m}^{-1}$. The present area averaged calculated conductivity for $14.5^{\circ} \mathrm{N}-19.5^{\circ} \mathrm{N}$ and $85.5^{\circ} \mathrm{E}-$ $90.5^{\circ} \mathrm{E}$ averaged for August 1990 and September 1990 is $\sim 1.99 \times$ $10^{-14} \mathrm{mho} \mathrm{m}^{-1}$. The order of magnitude sufficiently agrees with the measurements but the magnitude of the calculated $\lambda(\infty)$ is more. It is because the calculated conductivity (Figure SM 1a) is assumed to attain at the top of the electrode layer and not near the surface and continues throughout the boundary layer ${ }^{19}$. The calculated profile of vertical atmospheric electric potential using the present scheme of calculations too agrees well with the measured values ${ }^{39}$.The calculations (of the $\lambda(\infty)$ and that of $R_{\mathrm{c}}$ ) show that percent change in aerosol

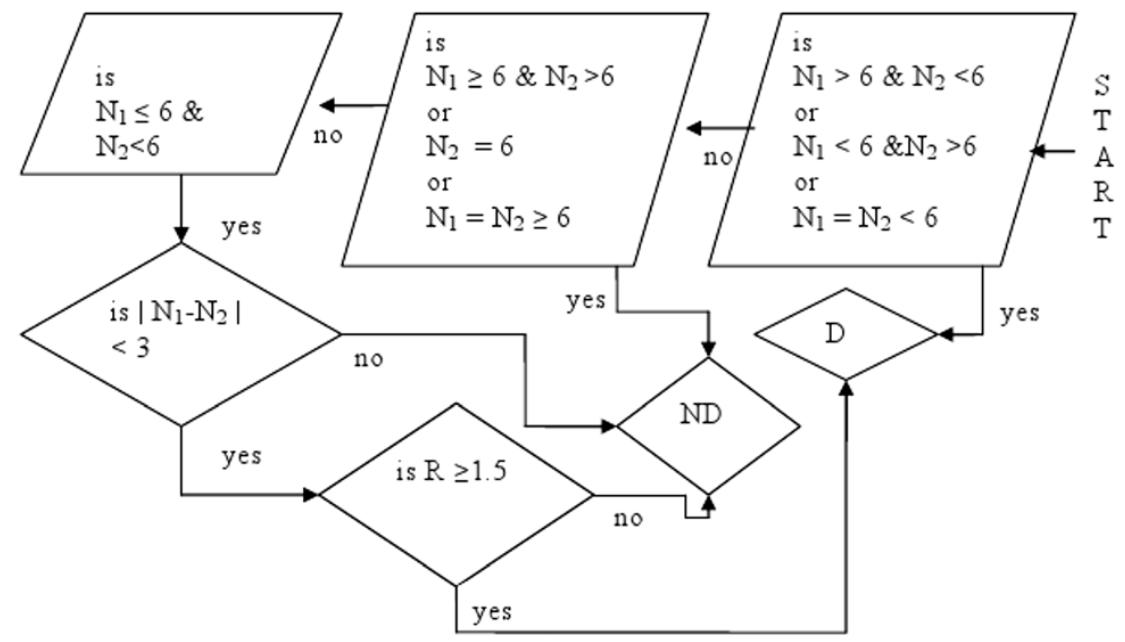

Figure 3 Method 2: A flow chart for predicting a drought over India as a whole. $N_{1}$ is the number of positive $A_{1}$ and $N_{2}$ is the number of positive $A_{2}$ in the previous year, $R=\operatorname{ABS}\left(A_{1}\right.$ maximum $) / \operatorname{ABS}\left(A_{1}\right.$ minimum) when $\operatorname{ABS}\left(A_{1}\right.$ maximum $)>\operatorname{ABS}\left(A_{1}\right.$ minimum $)$ and $R=\operatorname{ABS}\left(A_{1}\right.$ minimum $) /$ $\operatorname{ABS}\left(A_{1}\right.$ maximum $)$ when $\operatorname{ABS}\left(A_{1}\right.$ minimum $)>\operatorname{ABS}\left(A_{1}\right.$ maximum $)$. 'D' and 'ND' indicate 'drought' and 'no drought' conditions respectively for the running year. 
concentration creates almost one order more change in the resultant $R_{\mathrm{c}}$ values than the same percent change in the PBLH $(H)$. Table SM 1 shows the slope of the $R_{\mathrm{c}}$ plot when fitted linear for different conditions of the PBLH $(H)$ and the aerosol concentration $(Z)$. This shows that the change in aerosol concentration is the basic requirement for the appreciable change in the $R_{\mathrm{c}}$ to occur which is further amplified by the change in $H$.

When downward atmospheric electrical conduction current flowing from the ionosphere to the surface passes through the layer clouds, it generates space charge in conductivity gradients at the upper and lower boundaries and this electrical charge is capable of affecting the microphysical interactions between droplets and both ice-forming nuclei and condensation nuclei ${ }^{40}$. The conduction current is modulated by the changes in the columnar resistance. The change in the microphysical interactions caused by the change in the current may affect the droplet size and consequently the rain formation process. Also, the controlling parameters for the rain formation and the $R_{\mathrm{c}}$ variations are atmospheric aerosols and atmospheric convection. All these factors may contribute for the excellent association between the AIRF and the $R_{\mathrm{c}}$ (Figure SM 1 ).

The change in the microphysics of clouds may not create a major effect on the association (Figure SM $1 \mathrm{~b}$ and c) between the $R_{\mathrm{c}}$ and the $A I R F$ in the monthly dataset but may be attributed to the seasonal and intra-seasonal processes and consequent changes in the aerosol concentration and convection. As the meteorological conditions in the $\mathrm{BB}$ drives the monsoon circulation by supplying enough moisture, convection and advection of condensation nuclei, it is obvious that $R_{\mathrm{c}}$ over the $\mathrm{BB}$ which involves these parameters has excellent association with the rainfall over India. The Madden Julian oscillations (MJO) are the intra-seasonal oscillations of period 30-90 days and are responsible for the intra-seasonal variability of monsoon ${ }^{41}$. Since MJO is a large scale coupling between atmospheric circulation and tropical deep convection, it can modulate the $R_{\mathrm{c} \text {. Similarly, other }}$ convectively coupled Kelvin and Rossby waves are responsible for the variability on the scale of 10-30 days ${ }^{42}$. These two phenomena contribute for the seasonal and intra-seasonal variability of monsoon. The MJO modulates large scale convective activity throughout the tropics and modulates activity of tropical as well as worldwide cyclones $^{43}$. As the Kelvin waves are vertically propagating, they can affect the $R_{\mathrm{c}}$ by transporting aerosols to higher altitudes.

India receives about $80 \%$ rains from monsoon. The Indian monsoon season follows the pre-monsoon season of three months: March through May. The pre-monsoon season is accompanied with intense convective activity. This is the season in which the maximum variations and positive anomalies of $R_{\mathrm{c}}$ occur (Figure SM 4a and c). The positive precipitation anomalies occur during monsoon season (June through September) (Figure SM $4 \mathrm{~b}$ and $\mathrm{d}$ ). So, the $R_{\mathrm{c}}$ series is expected to correlate and lead the AIRF series by $1-3$ months as the pre-monsoon season is of three months (Figures SM 1b, c and d). Atmospheric aerosols serve as an inter-link between the meteorology and atmospheric electricity. Aerosols play a role in meteorology through a radiation balance which can cause changes in atmospheric circulation. They are also causative for microphysical interactions in clouds. In atmospheric electricity they play a role causing changes in electrical conductivity. This not only alters the $R_{\mathrm{c}}$ but electric field also. Thus regional meteorology and atmospheric electrical weather is controlled by aerosols. Table SM 2 shows the ionospheric potential measurements ${ }^{27}$ and the derived air-earth current densities $\left(I_{\mathrm{t}}\right)$. The derived $I_{\mathrm{t}} \mathrm{s}$ are consistent with the $I_{\mathrm{t}}$ measurements during March 2006 and during February, March, April, 2007 made at Tripura ${ }^{44}$ $\left(23.5^{\circ} \mathrm{N}, 91.25^{\circ} \mathrm{E}\right)$ and at Tirunelveli ${ }^{45}\left(8.7^{\circ} \mathrm{N}, 77.8^{\circ} \mathrm{E}\right)$ respectively. As Tirunelveli is in the south west of the region selected here, the incoming air over the $\mathrm{BB}$ around monsoon season may cross this region and so can represent the $I_{\mathrm{t}}$ values calculated in the present analysis. $I_{\mathrm{t}}$ is a parameter connecting global ionospheric potential and the regional $R_{\mathrm{c}}\left(V_{\mathrm{i}} / R_{\mathrm{c}}=I_{\mathrm{t}}\right)$. The anti-correlation between the $I_{\mathrm{t}}$ and the lag 3 AIRF (Figure SM 1d) is due to the reduced $R_{\mathrm{c}}$ and reduced number concentration of aerosols for an increase in the current density. One more physical possibility is, when the air is less conductive (more $R_{\mathrm{c}}$, less $I_{\mathrm{t}}$ ) due to ion-aerosol attachment in the presence of aerosols and also due to ion-ion recombination process, the amount of heat energy generated $(\Delta \mathrm{E})$ in these exothermic processes (ion-ion recombination and ion-aerosol attachment) can raise the temperature of the air by $\Delta \mathrm{T}$, which may intensify the circulation system causing favorable conditions for rain in the pre-monsoon period.

The filtered monthly $R_{\mathrm{c}}$ series using FFT band pass filter for the frequency range $0.0555-0.1$ (period of 10 months to 18 months) and leading by 8 months to the AIRF series has almost a fixed pattern of variation with the AIRF series (Figure SM 1e and $\mathrm{f}$ ). The analysis of the SST data during 1871-1998 of Indian ocean and the observed wind data during 1958-1998 shows that the Indian ocean dipole (IOD) is a regional phenomenon associated with the dynamics of Indian ocean independent of the ENSO. The wavelet power spectrum analysis of the data gives the periodicities of 10.1 months (95\% $>$ confidence level $\alpha>90 \%$ ) for the IOD dipole mode index and periodicities of 13.5, 16.4 (95\%> confidence level $\alpha>90 \%)$ and 17.9 months $(\alpha \geq 95 \%)$ for the ENSO index ${ }^{46}$. As, both these phenomena affect the rainfall over India, this could be the reason for very strong anti-correlation between the new predictor series filtered for the period 10-18 months and the AIRF series (Figures SM 1e, if and $3)$. Since the $R_{\mathrm{c}}$ increases/decreases with the increase/decrease in aerosol concentration and/or atmospheric convection, we consider the case of increasing trend of aerosol concentration for the period of 10-18 months. The increased aerosol concentration can form an aerosol layer over the region. The direct heat from the sun reaching the surface can get reduced causing consequent reduction in moisture supply. This can cause reduction in rainfall. So, the low frequencies of $R_{\mathrm{c}}$ (filtered $R_{\mathrm{c}}$ ) are in strong anti-correlation with the AIRF.

Thus, a short term increase in aerosols and convection in the BB as in pre-monsoon season favors the AIRF (Figure SM 1b, c, d) but a long term increase (frequencies corresponding to 10-18 months in the present analysis) in it does not favor the $\operatorname{AIRF}$ (Figure SM 1e and f).

The changes in $R_{\mathrm{c}}$ occur at a time scale too smaller than that for a rainfall to occur. Apart from the number of aerosols, there should be sufficient moisture and an instability for a rainfall event to occur. So, it is obvious that the variations of $R_{\mathrm{c}}$ will be followed by the rainfall variations. During a rainfall event, the aerosols in the atmosphere are settled down partially/fully which is again followed by a rebuild up of aerosols after the termination of the event and the cycle continues. Recent study ${ }^{47}$ (using observational data sets and sensitivity tests from the Community Atmosphere Model version 3.1 of the National Center for Atmospheric Research) on the variability of east Asian summer monsoon shows that the dipole mode pattern in the Indian and Pacific oceans affects the east Asian summer monsoon. The SSTA anomalies in the North Pacific are opposite to those in the Indo Pacific warm pool (the region considered here is a part of this warm pool) forming as a dipole. Along with this dipole the zonal oscillation of the western Pacific sub-tropical high (WPSH) occurs which controls the east Asian monsoon rainfall ${ }^{47}$. The WPSH can control the spatial distribution of aerosols through its movement and intensity. This could be the mechanism for the excellent association of the filtered $R_{\mathrm{c}}$ and the lag 8 AIRF. The dipole appears around May, becomes intense in successive months and weakens in September ${ }^{47}$. Thus, there is a time period of about 7-8 months (from September to May) for its reformation. This might have caused a lag of 8 months in the present analysis. Since aerosols have a seasonal cycle superimposed on it the local effects, the lag may vary spatially and temporally.

A dominant peak of the annual periodicity and two secondary peaks in the semi-annual frequency range in Figure SM 2a and c for the $R_{\mathrm{c}}$ time series may be due to the annual and the semi-annual variation of the GEC. The annual variation of the GEC is with northern hemisphere summer maximum occurring due to the asymmetry in 
land mass between northern and southern hemispheres accompanying global variation in air temperature ${ }^{8,48}$. The observed magnitude of the annual peak of the AC GEC i.e. of the Schumann resonance is about two fold and there is about $20 \%-30 \%$ increase in the various parameters of the DC GEC. The semi-annual secondary peaks are attributed to the enhancement of the tropical convection twice a year. This is due to the sun's equinoxial crossing of the equator two times in a year. As the amplitude of the semi-annual variation is greater than the quarter of the annual peak amplitude, they are visible ${ }^{8}$ in the periodogram.

Thus, asymmetry in the solar heating causes air circulations as well as variations in the GEC. The intense convective conditions in the $\mathrm{BB}$ drive Asian monsoon circulation. Also, the $R_{\mathrm{c}}$ series in the $\mathrm{BB}$ are well correlated with the AIRF series. Let us hypothesize that the seasonal monsoon rainfall over India may be predicted with the conditions in the $\mathrm{BB}$ alone. Figures 1 and 2 confirm this hypothesis. All the major drought years during the periods considered are identified successfully with the present predictor.

2012 is a special drought year in spite of the AIRF being $>90 \%$ (about 92\%) of the long period average (LPA). There was not any weekly prominent positive departure of rain during the period JuneAugust (Figure SM 7a). India suffered from severe agricultural drought during 2012 ${ }^{50}$ : The seasonal rainfall chart by India Meteorological Department is given at: (http://www.imd.gov.in/ section/nhac/dynamic/mon2012.jpg). The cumulative rainfall departure was more than $-25 \%$ during June and July and about $-25 \%$ in August up to middle of it. It was more than $-10 \%$ till $5^{\text {th }}$ September (almost end of the season) and then compensated afterwards up to 92\% of the LPA ${ }^{28}$ : (http://www.tropmet.res.in/ kolli/MOL/Monsoon/ frameindex.html). This special case is also identified in the present analysis (Figure 2). Such special cases in the future will confirm further the robustness of the present technique.

Year 2014 is also happened to be a special year. The seasonal rainfall is little less than $90 \%$ of LPA (about $88 \%$ of LPA i.e. $<90 \%)^{51}$ : The seasonal rainfall distribution is shown at: (http:// www.imd.gov.in/section/hydro/dynamic/rfmaps/seasonal/mon2014. jpg). So, according to the criterion of the Indian Institute of Tropical Meteorology (supplementary methods) if the seasonal AIRF in a year is $<90 \%$ of its LPA, the year is identified as all India major drought year. In reality, year 2014 is not being considered as all India major drought year. The conditions over the country as a whole are not severe due to good spells of rain during July and August. Unlike year 2012, there are weekly prominent positive departures (figure SM 7b) during July-August. Except in the month of June, in the following three months, the rainfall was at least $90 \%$ of the LPA. On the contrary, during 2012, though the seasonal rainfall was more than $90 \%$ of the LPA, the rainfall in July was $87 \%$ of the LPA. This shows that seasonal percentage of rainfall is not a strict sufficient condition to determine all India major drought conditions effectively. We can see that the overall effect for the country as a whole is better depicted in the results presented here. This is because the present technique uses all India rainfall for all the months and not the only seasonal one (southwest monsoon). The rainfall amount and spatial distribution during the months January-May along with the seasonal rainfall and its distribution (June-September) can produce the overall effect for the country. So, the present technique may be used independently to predict a drought over India.

In Figures 1 and 2 we can see the seasonal variation of irregularities in the $R_{\mathrm{c}}$ time series. These irregularities are caused due to the combined effect of long term changes and seasonal changes in the $R_{c}$. The irregularities in the predictor time series also have some mean state. When these irregular variations in a particular year are beyond their long term standard deviation, there is an occurrence of a drought in the forthcoming year. There are only two causative parameters for the $R_{\mathrm{c}}$ variations i.e. the PBLH $(H)$ and the total aerosol concentration $(Z)$. From Figure 1 we can say that the seasonal $\left(A_{2}\right)$ and the long term $\left(A_{1}\right)$ changes in the $R_{\mathrm{c}}$ determine the rainfall over India. Since the $R_{\mathrm{c}}$ is happened to be a very good predictor in the present analysis and is most sensitive to the changes in aerosol concentration, most of the rainfall variability over India could be considered due to the changes in aerosol concentration.

Since the present predictor involves atmospheric boundary layer height and atmospheric electrical conductivity, we can say that drought conditions are mainly determined by the strength of vertical convection, the ionization and ion-aerosol attachment processes in atmosphere. We see from the results, the periodogram of the $R_{\mathrm{c}}$ time series could be an outcome of the global electric circuit variations and that of the AIRF series is due to global monsoon circulation. Both these variations are temperature dependent and are due to an asymmetrical heating of the surface. This shows the importance of simulating atmospheric electrical conditions in climate prediction models.

\section{Method Summary}

The region $\left(14.5^{\circ} \mathrm{N}-19.5^{\circ} \mathrm{N}, 85.5^{\circ} \mathrm{E}-90.5^{\circ} \mathrm{E}\right)$ considered in the present analysis is a part of the Bay of Bengal. The area averaged time series of different parameters over the region have been used for the present purpose. The periods considered are January 1981-December 1990 and January 2001-December 2013.

Monthly planetary boundary layer height $(H)$ data which are used here are those produced by the Goddard Earth Observing System version 5 (GEOS-5) Modern Era Reanalysis for Research and Applications (MERRA) model. These data are available for free download from the Giovanni MERRA Monthly (2D) data collection (2/3 × 1 / 2 horizontal grids).

"Total Ozone Mapping Spectrometer" (TOMS) monthly aerosol optical depth (AOD) data have been used for the period 1981-1990. Moderate Resolution Imaging Spectra radiometer (MODIS) AOD Level 3 monthly collection 5.1 (051) data along with the data of angstrom exponent $(470 / 660 \mathrm{~nm})$ have been used for the period 2001-2013. AOD data have been used to derive aerosol concentration ${ }^{25,49}(Z)$.

The cosmic ray ionization is calculated for each latitude of $1^{\circ}$ resolution between $14.5^{\circ} \mathrm{N}$ to $19.5^{\circ} \mathrm{N}$ using the cosmic ray ionization profiles ${ }^{26}$ and then averaged to get the average profile at the top of the boundary layer.

From the derived aerosol concentration and the derived ionization, atmospheric electrical conductivity has been calculated (Supplementary equations). A standard value of scale height $(S)(10 / \mathrm{ln} 10 \mathrm{~km} \approx 4.34 \mathrm{~km})$ has been used for the calculations. The columnar resistance for the BB has been calculated from $H, S$ and the calculated conductivity $\lambda(\infty)$ as $R_{\mathrm{c}}=(H+S) / \lambda(\infty)$.

It has been found that Spearman's rank correlation coefficient of the filtered $R_{\mathrm{c}}$ time series (frequency range 0.0555 to 0.1 cycles per month) is very large and highly significant with the all India rainfall series when rainfall lags by 8 months. As FFT filter is not very accurate for the end point data, the analysis is also done with the recurrence filter using centered adjacent averaging to confirm.

As the irregular component and the trend in the predictor series are required for the present purpose of identification and prediction of drought years, the procedure of de-seasonalizing of $R_{\mathrm{c}}$ time series is carried out as follows: the long period average (LPA) for each of the months is calculated for each period separately. The average of the whole series has been subtracted from these individual LPA for each period separately. These resultant values have been subtracted again from the original series of respective months.

Finally, standardized anomalies are calculated from this de-seasonalized series for the whole period 1981-1990 and 2001-2013 $\left(A_{1}\right)$, and for the individual year $\left(A_{2}\right)$. $B(t)=A_{1}(\mathrm{t})+A_{2}(\mathrm{t})$ and $C(t)=A_{1}(\mathrm{t})-A_{2}(\mathrm{t})$ have been calculated and standardized for each period separately to predict a drought condition over India.

1. Goswami, B. N. The challenges of weather prediction: Difficulties in predicting weather. Resonance 2, 8-15 (1997).

2. Langenberg, H. Triggered lightning. Nature Geosci. 4, 140 (2011).

3. Yuan, T., Remer, L. A., Pickering, K. E. \& Yu, H. Observational evidence of aerosol enhancement of lightning activity and convective invigoration. Geophy. Res. Lett. 38, doi:10.1029/2010GL046052, L04701 (2011).

4. Wallace, J. M. \& Hobbs, P. V. Atmospheric Science - An Introductory Survey (Academic press, London, 1977).

5. Williams, E. R. The electrification of thunderstorms. Sci. Am. 259, 88-99 (1988)

6. Rycroft, M. J., Israelsson, S. \& Price, C. The global atmospheric electric circuit, solar activity and climate change. J. Atmos. Sol. Terr. Phys. 62, 1563-1576 (2000)

7. Wilson, C. T. R. Investigations on lightning discharges and the electric field of thunderstorms. Phil. Trans. A. 221, 73-115 (1920).

8. Williams, E. R. The global electrical circuit: A review. Atmos. Res. 91, 140-152 (2009).

9. Davydenko, S. S., Mareev, E. A., Marshall, T. C. \& Stolzenburg, M. On the calculation of electric fields and currents of mesoscale convective systems. J. Geophys. Res. 109, doi:10.1029/2003JD003832, 1-10 (2004).

10. Stolzenburg, M., Marshall, T. C., Rust, W. D., Mareev, E. A. \& Davydenko, S. S. [The stratiform precipitation region of mesoscale convective systems: inductive 
charging evidence and global circuit effects] $13^{\text {th }}$ International Conf. on Atmos. Elec. vol. 1, [13-16] (ICAE, Beijing, China 2007).

11. Bering, E. A., Few, A. A. \& Benbrook, J. R. The global electric circuit. Phys. Today. 51, 24-30 (1998).

12. Rycroft, M. J. et al. New model simulations of the global atmospheric electric circuit driven by thunderstorms and electrified shower clouds: The roles of lightning and sprites. J. Atmos. Sol. Terr. Phys. 69, 2485-2509 (2007).

13. Williams, E. R. The Schumann resonance: a global tropical thermometer. Science 256, 1184-1187 (1992).

14. Markson, R. \& Price, C. Ionospheric potential as a proxy index for global temperature. Atmospheric Research. 51, 309-314 (1999).

15. Markson, R. Tropical convection, ionospheric potentials and global circuit variation. Nature 320, doi: 10.1038/320588a0, 588-594 (1986)

16. Gish, O. H. Evaluation and interpretation of the columnar resistance of the atmosphere. Terr. Mag. And Atm. Ele. 49, 159-168 (1944).

17. Harrison, R. G. Columnar resistance changes in urban air. J. Atm. Sol. Terr. Phys. 67, 763-773 (2005).

18. Anderson, R. V. [Atmospheric electricity in the real world] Proceedings of the $5^{\text {th }}$ International Conference on Atmospheric Electricity [Dolezalek, H. and Reiter, R. (ed.)] [87] (Steinkopff Verlag, Heidelberg, Germany, 1977).

19. Kulkarni, M. N. A new empirical relation to estimate atmospheric electrical columnar resistance, effect of changing aerosol concentration and cosmic ray ionization on it: A quantitative study. J. Geophys. Res. 114, doi:10.1029/ 2008JD010009, 1-13 (2009).

20. Hoppel, W. A. Theory of the electrode effect. J. Atm. Terr. Phy. 29, 709-721 (1967).

21. Hoppel, W. A. \& Gathman, S. G. Determination of eddy diffusion coefficient from atmospheric electrical measurements. J. Geophys. Res. 76, 1467-1477 (1971).

22. Kulkarni, M. \& Kamra, A. K. Vertical profiles of atmospheric electrical parameters close to ground. J. Geophy. Res. 106, 28209-28221 (2001).

23. Kulkarni, M. N. On the modeling of electrical boundary layer (electrode layer) and derivation of atmospheric electrical profiles, eddy diffusion coefficient and scales of electrode layer. J. Earth Syst. Sci. 119, 75-86 (2010).

24. Hoppel, W. A., Anderson, R. V. \& Willett, J. C. [Atmospheric electricity in the planetary boundary layer] The earth's Electrical Environment [149-165] (Natl. Acad. Press, Washington, D. C., 1986).

25. Andreae, M. O. Correlation between cloud condensation nuclei concentration and aerosol optical thickness in remote and polluted regions. Atmos. Chem. Phys. 9, 543-556 (2009)

26. Makino, M. \& Ogawa, T. Quantitative estimation of global circuit. J. Geophys. Res. 90, 5961-5966 (1985).

27. Markson, R. The global circuit intensity: Its measurement and variation over the last 50 years. Bull. Am. Met. Soc. 88, doi:10.1175/BAMS-88-2-223, 223-241 (2007).

28. Munot, A. A. \& Kothawale, D. R. Monsoon On Line http://www.tropmet.res.in/ $\sim$ kolli/MOL/Monsoon/frameindex.html (2010) (13/05/2014).

29. Misra, V., Pantina, P., Chan, S. C. \& DiNapoli, S. A comparative study of the Indian summer monsoon hydro-climate and its variations in three re-analyses. Clim. Dyn. 39, doi: 10.1007/s00382-012-1319-y, 1149-1168 (2012).

30. Webster, P. et al. The JASMINE pilot study. Bull. Amer. Meteor. Soc. $\mathbf{8 3}$ 1603-1630 (2002).

31. Brubaker, K. L. et al. Estimation of continental precipitation recycling. J. Climate. 6, 1077-1089 (1993)

32. Budyko, M. I. Climate and life (Academic Press, London, 1974).

33. Benton, G. S. et al. The role of the atmosphere in the hydrologic cycle. Trans Am. Geophys. Union. 31, 61-73 (1950).

34. Zuidema, P. Convective clouds over the Bay of Bengal. Mon. Wea. Rev. 131, 780-798 (2003).

35. Sperber, K. R. \& Palmer, T. Inter-annual tropical rainfall variability in general circulation model simulations associated with the atmospheric model intercomparison project. J. Climate. 9, 2727-2750 (1996).

36. Roca, R. \& Ramanathan, V. Scale dependence of monsoonal convective systems over the Indian Ocean. J. Climate. 13, 1286-1298 (2000).

37. Kamra, A. K. \& Deshpande, C. G. Possible secular change and land-to-ocean extension of air pollution from measurements of atmospheric electrical conductivity over the Bay of Bengal. J. Geophys. Res. 100, 7105-7110 (1995).

38. Kamra, A. K., Deshpande, C. G. \& Gopalakrishnan, V. Challenge to the assumption of the unitary diurnal variation of the atmospheric electric field based on observations in the Indian Ocean, Bay of Bengal, and Arabian Sea. J. Geophys. Res. 99, 21043-21050 (1994).
39. Kulkarni, M. N. \& Kamra, A. K. A model for calculating the vertical distribution of the atmospheric electric potential in the exchange layer in a maritime clean atmosphere. Adv. Space. Res. 50, 1231-1240 (2012).

40. Tinsley, B. A., Burns, G. B. \& Zhou, L. The role of the global electric circuit in solar and internal forcing of clouds and climate. Adv. Space. Res. 40, 1126-1139 (2007).

41. Sikka, D. R. \& Gadgil, S. On the maximum cloud zone and the ITCZ over Indian longitudes during the south west monsoon. Mon. Wea. Rev. 108, 1840-1853 (1980).

42. Duncan, B. \& Han, W. Indian Ocean intra-seasonal sea surface temperature variability during boreal summer: Madden-Julian Oscillation versus sub-monthly forcing and processes. J. Geophys. Res. 114, doi:10.1029/2008JC004958, 1-22 (2009).

43. Klotzbach, P. J. The Madden-Julian Oscillation's impacts on worldwide tropical cyclone activity. J. Climate. 27, 2317-2330 (2014).

44. Guha, A., De, B. K., Gurubaran, S., De, S. S. \& Jeeva, K. First results of fair-weather atmospheric electricity measurements in northeast India. J. Earth Syst. Sci. 119, $221-228(2010)$

45. Anil Kumar, C. P., Panneerselvam, C., Nair, K. U. et al. Measurement of atmospheric air-earth current density from a tropical station using improvised Wilson's plate antenna. Earth Planets Space 61, 919-926 (2009).

46. Ashok, K., Guan, Z. \& Yamagata, T. A look at the relationship between the ENSO and the Indian Ocean Dipole. J. Meteorol. Soci. Japn. 81, 41-56 (2003).

47. Zheng, J., Li, J. \& Feng, J. A dipole pattern in the Indian and Pacific oceans and its relationship with the east Asian summer monsoon. Environ. Res. Lett. 9, doi:10.1088/1748-9326/9/7/074006, 1-9 (2014).

48. Williams, E. R. Global circuit response to seasonal variations in global surface air temperature. Mon. Wea, Rev. 122, 1917-1929 (1994).

49. Khan, A., Qureshi, S. \& Blaschke, T. Monitoring spatio-temporal aerosol patterns over Pakistan based on MODIS, TOMS and MISR satellite data and a HYSPLIT model. Atmos Environment. 45, doi: 10.1016/j.atmosenv.20011.05.055, 4641-4651 (2011).

50. Hydromet Division, New Delhi, India Meteorological Department India Meteorological Department http://www.imd.gov.in/section/nhac/dynamic/ mon2012.jpg (2013) (01/10/2014).

51. Hydromet Division, New Delhi, India Meteorological Department India Meteorological Department http://www.imd.gov.in/section/hydro/dynamic/ rfmaps/seasonal/mon2014.jpg (2014) (01/10/2014).

\section{Acknowledgments}

The author sincerely acknowledges the National Oceanic and Atmospheric Administration (NOAA), Washington, DC 20230 and the National Aeronautics and Space Administration (NASA), Washigton, DC 20546-0001 for making available the global data sets used here. Also, the author acknowledges the Indian Institute of Tropical meteorology (IITM) for making available the regional data. Special thanks to Dr. J. V. Revadekar, IITM for preparing monsoon charts and to all 'Monsoon On Line' team members. Finally, the author acknowledges the financial support from the Ministry of Earth Sciences, India and from the Director, IITM. The author has used Microcal Origin and 'R' statistical software and GIMP for the data analysis and figures.

\section{Author contributions}

M.N.K. has done all the preliminary work and has revised the manuscript.

\section{Additional information}

Supplementary information accompanies this paper at http://www.nature.com/ scientificreports

Competing financial interests: The authors declare no competing financial interests.

How to cite this article: Kulkarni, M.N. A new tool for predicting drought: An application over India. Sci. Rep. 5, 7680; DOI:10.1038/srep07680 (2015).

This work is licensed under a Creative Commons Attribution-NonCommercialShareAlike 4.0 International License. The images or other third party material in this article are included in the article's Creative Commons license, unless indicated otherwise in the credit line; if the material is not included under the Creative Commons license, users will need to obtain permission from the license holder in order to reproduce the material. To view a copy of this license, visit http:// creativecommons.org/licenses/by-nc-sa/4.0/ 